\title{
Perinatal Outcome in Pregnancies Complicated by Isolated Oligohydramnios at Term
}

UMBER A.

Aneela_dr@yahoo.com

Objective: To determine the perinatal outcome in pregnancies complicated by isolated oligohydramnios at term.

Study Design: Comparative / Cohort study.

Place and Duration of Study: This study was carried out in Unit-III at Sir Ganga Ram Hospital, Lahore from 14-05-2002 to15-06-2003.

Patients and Methods: During this study 500 patients with singleton pregnancy were selected and Amniotic Fluid Index (AFI) was evaluated within 4 days of delivery in these patients with technique of Phelan et al. All selected outcome variables of these pregnancies were recorded on printed proformas. On the bases of AFI measurements patients were divided in two groups. Those who have AFI $>50 \mathrm{~mm}$ and $\leq 50 \mathrm{~mm}$. The significance of difference or comparison of means was measured by Chai square test (by Yats corrections). Perinatal outcomes in pregnancies with oligohydramnios were compared with those with normal amniotic fluid volume.

Results: The selected outcomes showed significant variations in both groups. The statistical significance was present between advanced gestational age, presence of meconium, deceleration of fetal heart rate and chances of caesarean delivery. There were increased chances of induction of labor (41\% Vs $22 \%)$ and caesarean delivery $(32 \% \mathrm{Vs} 23 \%)$ in oligohydramnios group.

Conclusion: Oligohydramnios is associated with an increased risk of caesarean delivery for fetal distress and perinatal morbidity.

Key Words: Isolated Oligohydramnios, perinatal outcome.

\section{INTRODUCTION}

Oligohydramnios defined as an AFI $\leq 5^{\text {th }}$ centile for the gestational age, AFI $\leq 50 \mathrm{~mm}$ or maximum vertical pocket devoid of umbilical cord or fetal limbs measure $<30 \mathrm{~mm}$, in the presence of intact membranes is a common obstetric complication, occurring in $3-5 \%$ of pregnancies at term. Some authors ${ }^{1-4}$ state that such pregnancies are at an increased risk of adverse perinatal outcome such as fetal distress in labor, induction of labor, cesarean delivery for fetal distress, meconium passage, low Apgar score and neonatal resuscitation or neonatal intensive care unit admission. But others ${ }^{5-8}$ have not confirmed the association of adverse perinatal outcome with oligohydramnios; Instead they state that isolated oligohydramnios is not associated with adverse perinatal outcome. The objective of this study was to determine the association of isolated oligohydramnios at term with adverse perinatal outcome.

\section{Aims and Objectives}

To determine the perinatal outcome in pregnancies complicated by isolated oligohydramnios at term.

\section{Patients \& Methods}

This study was carried-out in the Department of Obstetrics and Gynecology Unit III, Sir Ganga Ram Hospital Lahore during one year period from 14.05.2002 to 15.06.2003.
During this study 500 patients were selected, booked or unbooked attending antenatal clinic or labor room of Unit III in Sir Ganga Ram Hospital Lahore. Inclusion criteria for the study population was: women with singleton pregnancy with well established dates, at 40.0-42.0 weeks gestational age (GA), fetus with no anomalies, amniotic fluid volume evaluated within 4 days of delivery in these patients, and determination of amniotic fluid volume with technique of Phelan et $\mathrm{al}^{(9)}$. Following patients were excluded from the study: Patients with less than 40 weeks and unsure gestational age, patients with multiple pregnancy, patients with history of preterm rupture of membranes, patients with preeclampsia and uncontrolled gestational diabetes, and delivery after 4 days of evaluation of amniotic fluid volume.

Amniotic fluid measurements were performed by ultrasound on targeted patients. Equipment used in this study included Acuson model machine which was equipped with 3.5 and 5.0-MHz curvilinear transducers.

Estimates of amniotic fluid volume were recorded by means of AFI described by Phelan et $\mathrm{al}^{9}$. AFI values of $\leq 50$ $\mathrm{mm}$ were interpreted to represent oligohydramnios. All selected outcome variables of these pregnancies were recorded on printed proformas in the hospital, which were shifted to computer for analysis. Selected outcome variables included: spontaneous vaginal delivery, abnormal non-stress testeither with decelerations or non-reactive, instrumental 
Table 1: Selected Outcomes in Women with $\leq 50 \mathrm{~mm}$ (Oligohydramnios) and Women with AFI $>50 \mathrm{~mm}$.

\begin{tabular}{|l|c|c|c|}
\hline \multicolumn{1}{|c|}{ Outcomes } & $\begin{array}{c}\text { AFI } \leq \mathbf{5 0} \mathbf{~ m m} \\
(\mathbf{n}=\mathbf{1 4 7}) \mathbf{( 2 9 . 4 \% )}\end{array}$ & $\begin{array}{c}\text { AFI }>\mathbf{5 0} \mathbf{~ m m} \\
(\mathbf{n}=\mathbf{3 5 3}) \mathbf{( 7 0 . 6 \% )}\end{array}$ & $\begin{array}{c}\text { Statistical } \\
\text { Significance }\end{array}$ \\
\hline Induction of labor & $61(41 \%)$ & $77(22 \%)$ & $\mathrm{p}>0.1^{*}$ \\
\hline 1. $\quad$ Gestational age 42 weeks & $12(8 \%)$ & $37(10.4 \%)$ & $\mathrm{p}<0.001^{* *}$ \\
\hline 2. $\quad$ Non-reassuring fetal heart rate & $7(4.7 \%)$ & $10(2.8 \%)$ & $\mathrm{p}>0.5^{*}$ \\
\hline 3. $\quad$ Deceleration of fetal heart rate & $71(48 \%)$ & $137(38.8 \%)$ & $\mathrm{p}<0.001^{* *}$ \\
\hline 4. $\quad$ Meconium. & $9(6 \%)$ & $30(8.5 \%)$ & $\mathrm{p}<0.001^{* *}$ \\
\hline 5. $\quad$ Caesarean delivery & $47(32 \%)$ & $81(23 \%)$ & $\mathrm{p}<0.01^{* *}$ \\
\hline 6. $\quad$ Apgar score $<6$ at 1 min. & $12(8 \%)$ & $4(1.1 \%)$ & $\mathrm{p}>0.05^{*}$ \\
\hline 7. $\quad$ Apgar score $<7$ at 5 min. & $9(6 \%)$ & $2(0.56 \%)$ & $\mathrm{p}>0.05^{*}$ \\
\hline 8. $\quad$ Resuscitation required. & $5(3.4 \%)$ & $3(0.84 \%)$ & $\mathrm{p}>0.5^{*}$ \\
\hline 9. $\quad$ Admission to Intensive Care Nursery. & $10(7 \%)$ & $6(1.7 \%)$ & $\mathrm{p}>0.3^{*}$ \\
\hline 10. Birth weight 2.5 to 3.9 Kg. & $90(61 \%)$ & $285(80.7 \%)$ & $\mathrm{p}<0.001^{* *}$ \\
\hline 11. Birth weight $\geq 4$ Kg. & $4(2.7 \%)$ & $35(10 \%)$ & $\mathrm{p}<0.001^{* *}$ \\
\hline
\end{tabular}

delivery for fetal distress (forceps delivery, cesarean delivery $), 1$ minute Apgar score $\leq 6(1 \mathrm{~min}<$ or $=$ to 6$), 5$ minute Apgar score $\leq 7(5 \mathrm{~min}<$ or $=$ to 7$)$, presence of meconium, resuscitation, birth weight, and neonatal intensive care unit admission (NICU).

The data analysis was computer based using SPSS statistical package. On the basis of division of patients with AFI $\leq 50 \mathrm{~mm}$ and the particular outcome, tables were constructed and the relative risk for each calculated. Oligohydramnios was defined as an amniotic fluid index $\leq 50 \mathrm{~mm}$. Perinatal outcomes in pregnancies with oligohydramnios were compared with those with an amniotic fluid index of $>$ $50 \mathrm{~mm}$.

\section{Results}

Patients were divided in 2 groups on the basis of AFI measurements, those who have AFI $>50 \mathrm{~mm}$ and $\leq 50 \mathrm{~mm}$; nearly $70 \%$ of patients showed values of AFI above $50 \mathrm{~mm}$ and $29 \%$ of patients showed AFI $\leq 50 \mathrm{~mm}$ (Oligohydramnios).

The selected outcomes showed significant variations in both groups. Oligohydramnios was associated with increased chances of induction of labor ( $41 \%$ Vs $22 \%)$, non reassuring fetal heart rate $(4.7 \%$ Vs $2.8 \%)$, decelerations of fetal heart rate $(48 \% \mathrm{Vs} 38.8 \%)$, caesarean delivery for fetal distress $(32 \%$ Vs $23 \%)$, Apgar score $<6$ at $1 \mathrm{~min}(8 \% \mathrm{Vs}$ $1.1 \%$ ), Apgar score $<7$ at 5 , but the statistical significance was only present between advanced gestational age, pre- sence of meconium, deceleration of fetal heart rate and chances of caesarean delivery(table 1).

\section{Discussion}

Since long oligohydramniosn has long been correlated with adverse perinatal outcome, such as increased risk of intrauterine growth restriction ${ }^{10,11}$ congenital abnormalities, postdates pregnancy ${ }^{12,13}$ meconium passage ${ }^{14}$ abnormal fetal heart rate patterns, and lower Apgar scores. ${ }^{15}$

The study results analysis demonstrate that oligohydramnios is associated with increased chances of induction of labor $(41 \%$ Vs $22 \%)$, non reassuring fetal heart rate $(4.7 \%$ Vs $2.8 \%)$, decelerations of fetal heart rate $(48 \%$ Vs $38.8 \%)$, caesarean delivery ( $32 \%$ Vs $23 \%$ ), Apgar score $<6$ at $1 \mathrm{~min}$ ( $8 \%$ Vs $1.1 \%$ ), Apgar score $<7$ at 5 min (6\% Vs $0.56 \%$ ), neonatal resuscitation $(3.4 \%$ Vs $0.84 \%)$ and neonatal ICU admission (7\% Vs 1.7\%).

The results are favoured by a study by Rutherford et' $\mathrm{al},{ }^{15}$ who observed an association between adverse perinatal outcome and oligohydramnios indicating that non-reactive non-stress tests (NST), FHR decelerations, meconium staining of amniotic fluid, cesarean section for fetal distress, and low Apgar scores are more common in patients with oligohydramnios. Similarly Sarno et $\mathrm{al}^{16}$ found that intrapartum oligohydramnios was associated with an increased risk of cesarean delivery for fetal distress, an Apgar score $<7$ at 1 'minute and abnormal fetal heart rate patterns.

However Grubb and Paul ${ }^{17}$ did not observe such asso- 
ciation (no significant increase in intervention for fetal distress, either cesarean or operative vaginal delivery, in patients with oligohydramnios (AFIs of 20 to $49 \mathrm{~mm}$ ) when compared to those with normal amniotic fluid volume (AFI of $50 \mathrm{~mm}$ or more). Similarly Chauhan et al ${ }^{18,19}$ failed to find an increased risk for cesarean delivery for fetal distress or low Apgar scores in patients with oligohydramnios.

However, although the study results analysis demonstrate that oligohydramnios is associated with increased chances of induction of labor, non reassuring fetal heart rate, decelerations of fetal heart rate, caesarean delivery, Apgar score $<6$ at $1 \mathrm{~min}$, Apgar score $<7$ at $5 \mathrm{~min}$, neonatal resuscitation and neonatal ICU admission, yet the statistical significance was only present between advanced gestational age, presence of meconium, deceleration of fetal heart rate and chances of caesarean delivery.

The most important constrain to influence the decision to proceed with caesarean delivery is objective interpretation of fetal heart rate tracing. Similarly, the caesarean delivery for fetal distress would be preferable only after a fetal scalp $\mathrm{pH}$ value is obtained. ${ }^{18}$ However, because of non trained personnel, non-availability of the machine, cervical dilatation, or other constraints, the fetal $\mathrm{pH}$ may not be attainable before emergency caesarean delivery. Similarly a low Apgar score may be the result of use of narcotics in labor, pre-term birth, or vigorous suctioning of the neonate. Similar results have been shown by Elizabeth et al ${ }^{(20)}$ and Morrris et al. ${ }^{21}$ Further studies are required to determine the association of isolated oligohydramnios at term with adverse perinatal outcome.

\section{Conclusion}

Oligohydramnios (AFI $\leq 50 \mathrm{~mm}$ ) is associated with an increased risk of caesarean delivery for fetal distress and poor Apgar scores.

\section{References}

1. Chamberlain PF, Manning FA, Morrison I, et al. Ultrasound evaluation of amniotic fluid volume. Am J Obstet Gynecol. 1984; 150: 245-249.

2. Chamberlain PF, Manning FA, Morrison I, et al. Ultrasound evaluation of amniotic fluid volume II the relationship of increased amniotic fluid volume to perinatal outcome. Am J Obstet Gynecol. 1984; 150: 250-254.

3. Banks EH, Miller DA. Perinatal risks associated with borderline AFI. Am J Obstet Gynecol. 1999 Jun; 18: 1461-3.

4. Casey BM. Pregnancy outcomes after antepartum diagnosis of oligohydramnios at or beyond 34 weeks' gestation. Am J Obstet Gynecol. 2000; 182: 909-12.

5. Locatelli A, Zaqarella A, Toso L, Assi F, Ghidini A, Biffi A. Serial assessment of AFI in uncomplicated term pregnancies: Prognostic value of amniotic fluid reduction. J Matern Fetal Neonatal Med 2004; 15: 2336.

6. Chauhan SP, Hendrix NW, Morrison JC, Magann EF, Devoe LD. Intrapartum oligohydramnios does not pre- dict adverse peripartum outcome among high risk parturient. Am J Obstet Gynaecol 1997; 176: 1130-8.

7. Rainford M, Adair R, Scialli AR, Ghidini A, Spongy CY. Amniotic fluid index in the uncomplicated term pregnancy. Prediction of outcome. J Reprod Med. 2001 Jun; 46 (6): 589-92.

8. Ott WJ. Re-evaluation of the relationship between amniotic fluid volume and perinatal outcome. Am J Obstet Gynecol 2005; 192: 1803-9.

9. Phelan JP, Smith CV, Broussard P, Small M. Amniotic fluid volume assessment with the four quadrant technique at 36-42 weeks gestation. J Reprod Med 1987; 32: $540-2$.

10. Manning FA, Hill LM, Platt LD. Qualitative. Oligohydramnios: clinical association and predictive value for amniotic fluid volume determination by ultrasound: antepartum detection of intrauterine growth retardation. Am J Obstet Gynecol 1981; 139: 254-8.

11. Philipson EH, Sokol RJ, Williams T intrauterine growth retardation. Am J Obstet Gynecol 1983; 146: 271-6.

12. Crowley P. Non-quantitative estimation of amniotic fluid volume in suspected prolonged pregnancy. J Perinat Med 1980; 8: 249-51.

13. Phelan JP, Platt LD, Yeh S-Y, Broussard P, Paul RH. The role of ultrasound assessment of amniotic fluid volume in the management of the postdate pregnancy. Am J Obstet Gynecol 1985; 151: 304-8.

14. Divon MY, Marks AD, Henderson C. Longitudinal measurement of amniotic fluid index in postterm pregnancies and its association with fetal outcome. Am J Obstet Gynecol 1995; 172: 142-6.

15. Rutherford SE, Phelan JP, Smith CV, Jacobs N. The four-quadrant assessment of amniotic fluid volume: an adjunct to antepartum fetal heart rate testing. Obstet Gynecol 1987; 70: 353-6.

16. Sarno AP, Ahn MO, Phelan JP. Intrapartum amniotic fluid volume at term: association of ruptured membranes, oligohydramnios, and increased fetal risk. $J$ Reprod Med 1990; 35: 719-23.

17. Grubb DK, Paul RH. Amniotic fluid index and prolonged antepartum fetal heart rate decelerations. Obstet Gynecol 1992; 79: 558-60.

18. Chauhan SP, Cowan BD, Magann EF et al. Intrapartum amniotic fluid index: a poor diagnostic test for adverse perinatal outcome. J Reprod Med 1996; 41: 860-6.

19. Chauhan SP, Magann EF, Perry KG, Morrison JC. Intrapartum amniotic fluid index and two-diameter pocket are poor predictors of adverse neonatal outcome. J Perinat 1997; 17: 221-4.

20. Elizabeth G Voxman, Susan Tran, Deborah. Low amniotic fluid index as a predictor of adverse perinatal outcome. Journal of Perinatology 2002; 22: 282-5.

21. Morris et al. The usefulness of ultrasound assessment of AFI in predicting adverse outcome in prolonged pregnancy: A prospective blinded observational study. BJOG 2003; 110: 989-94. 